\title{
The Hip Restoration Algorithm
}

\author{
Allston Julius Stubbs \\ Halis Atil Atilla
}

Department of Orthopaedics, Wake Forest University Baptist Medical Center, Winston Salem, USA

Corresponding author:

Halis Atil Atilla

Department of Orthopaedics, Wake Forest University Baptist Medical Center, Winston Salem, USA

E-mail: dratilatilla@hotmail.com

\section{Summary}

Background: Despite the rapid advancement of imaging and arthroscopic techniques about the hip joint, missed diagnoses are still common. As a deep joint and compared to the shoulder and knee joints, localization of hip symptoms is difficult. Hip pathology is not easily isolated and is often related to intra and extra-articular abnormalities. In light of these diagnostic challenges, we recommend an algorithmic approach to effectively diagnoses and treat hip pain.

Methods: In this review, hip pain is evaluated from diagnosis to treatment in a clear decision model. First we discuss emergency hip situations followed by the differentiation of intra and extraarticular causes of the hip pain. We differentiate the intra-articular hip as arthritic and non-arthritic and extra-articular pain as surrounding or remote tissue generated. Further, extra-articular hip pain is evaluated according to pain location. Finally we summarize the surgical treatment approach with an algorithmic diagram.

Conclusion: Diagnosis of hip pathology is difficult because the etiologies of pain may be various. An algorithmic approach to hip restoration from diagnosis to rehabilitation is crucial to successfully identify and manage hip pathologies. Level of evidence: $\mathrm{V}$.

KEY WORDS: hip pain, differential diagnosis, management, arthroscopy.

\section{Introduction}

Over the past 25 years, much ground has been covered in the field of native hip preservation. In the last decade, there have been significant efforts directed to- ward preserving the hip joint. Some of the reasons behind the interest in hip preservation are the early onset of hip problems associated with the institutionalization of sport at the early ages of life and increasing activities of young people which encourage supraphysiologic range of motion. There has been improved recognition of the problem by medical professionals with high technology imaging techniques and a better educated patient population. Further, increased life expectancy encourages us to preserve and restore the native hip as long as possible. While there is one outcome for the end-stage arthritic hip, there are many etiologies of hip degeneration or hip pain. Consequently, an algorithmic approach to hip restoration from diagnosis to rehabilitation is crucial to successfully identify and address prearthritic hip problems.

\section{Diagnostic algorithm}

To ensure the best outcome of hip restoration the approach comprises four components: history, physical examination, radiology/laboratory and understanding patient expectations. Every type of pathology can be evaluated by this method called "HERE" (History, Examination, Radiology- laboratory, Expectation of patients). The first step of the diagnostic algorithm is to figure out the urgency of the pathology.

\section{Emergency hip pain}

The most important step of hip pain evaluation is the differentiation of emergency hip conditions from nonemergency conditions.

Subluxation associated hip effusion: Space occupying pathologic conditions in hip joint can force the head out from acetabulum and should be addressed urgently in order to prevent dislocation and possible avascular necrosis ${ }^{1}$. It is more common in children but major effusion of the hip is not uncommon in adults ${ }^{2}$.

Tips (HERE) History: Very painful, with or without a trauma history. Pain in the groin or medial thigh Examination: Decreased and painful of range of motion. Pain aggravated by lying on the side, Flexed, internal rotated position of the hip. Radiology: Increased joint space, with US effusion and MRI space occupying lesion. Expectation: Immediately reducing the pain of the hip without sequelae.

Stress Fractures: Femoral neck stress fractures are less common but require early diagnosis to prevent displacement and avascular necrosis of the femoral head. They present in two age groups: one is young, 
active healthy individuals who has a history of overloading by sports or military activities. The other group is the elderly females who suffer from osteopenia or osteoporosis ${ }^{3}$.

Tips (HERE) History: Young active, overloading sport activities, military recruits. Elderly: Caucasian, female, osteoporosis. Examination: Nonspecific hip pain and pain with weight bearing. Radiology: Scintigraphy, MRI, Bone Mineral Densitometry. Expectation of Patient: Young; returning sports immediately, Elderly; avoiding from repeating surgeries and early mobilization.

Hip Joint Infection: Septic arthritis is an important and serious condition of the growing hip because of its high potential to cause permanent sequelae ${ }^{4}$. The most common joint infection in infants and in the young is the hip joint. In children differentiation of septic arthritis from transient synovitis is important as transient synovitis resolves spontaneously while the septic arthritis needs operative treatment ${ }^{5}$. Although septic arthritis of the hip is primarily recognized in children, it can be seen in adolescents and adults. Delayed or inadequate treatment of septic arthritis in adults can lead to irreversible joint destruction, dissemination of the infection, and death with a rate of $11 \%{ }^{6}$. Gonococcal arthritis is the most common form of septic arthritis in United States. It is rarely associated with joint destruction which is common in Staphylococcus aureus septic arthritis ${ }^{7}$.

Tips (HERE) History: Children: Irritability, fever, nonweight bearing. Decline in general medical status. Adolescents and Adults: Sexual activity, rheumatoid arthritis or osteoarthritis, joint prosthesis, low socioeconomic status, intravenous drug abuse, alcoholism, diabetes, previous intra-articular corticosteroid injection, cutaneous ulcers. Examination: Decreased and painful of range of motion. Avoidance of weight bearing. Flexed, internally rotated position of the hip. Fever. Radiology, Laboratory: US and MRI, Elevated ESR, WBC.

Expectation: Elimination of the microorganisms from the joint without having a permanent sequelae or dissemination.

Slipped Capital Femoral Epiphysis (SCFE): There are stages as pre slip, acute, chronic, and acute on chronic of the condition. The clinical presentation differs from stage to stage. Early suspicion is crucial in diagnosis. Early diagnosis and fixation may prevent arthritis ${ }^{8}$.

Tips (HERE) History: In the pre-slip stage, weakness in the leg, limping, or pain in the groin are dominant; in the acute stage, antalgic gait and loss of range of motion are dominant presentations. Endocrine disorder. Examination: Obesity, Black Male (higher incidence), Age: 9-16. Antalgic gait, Lack of internal rotation, abduction and flexion. Radiology, Laboratory: XR: Preslip: Non-specific, Acute: Slip at Frog leg views. MRI is worthwhile especially at early stages. Expectation: Protecting from further slipping and early arthritis.

Dislocation and Fracture: Diagnosis is not a real challenge though presentation and history of trauma.

Tips (HERE) History: Trauma Examination: Painful motion, deformity. Radiology/Laboratory: In some cases, the fracture line cannot be differentiated with standard X-ray plain films Standard pelvis and inlet, outlet views and Judet views of acetabulum are required. CT is helpful in most cases to identify fracture patterns and loose bodies. Expectation: Reduction with or without fixation.

\section{Non emergency hip pain}

After elimination of emergency causes of hip pain, we determine if the pain generator is intraarticular or extraarticular with the help of history and physical examination. Though the hip is a deep and complex structured joint there are many structures around the hip that can cause hip pain and disability. On the other hand, there are many other extra articular remote pathologies that may causes hip pain, radiate, or affect the hip joint (Figure 1). Hip pathologies may mimic other organ pathologies or hip pain can radiate.

I. Differentiation of intraarticular pathologies from extraarticular: The most important clinical tools are history and physical examination. If there is hip pain with Byrd's "C-sign", loss of range of motion: asymmetry in hip motions, positive provocative tests, func-

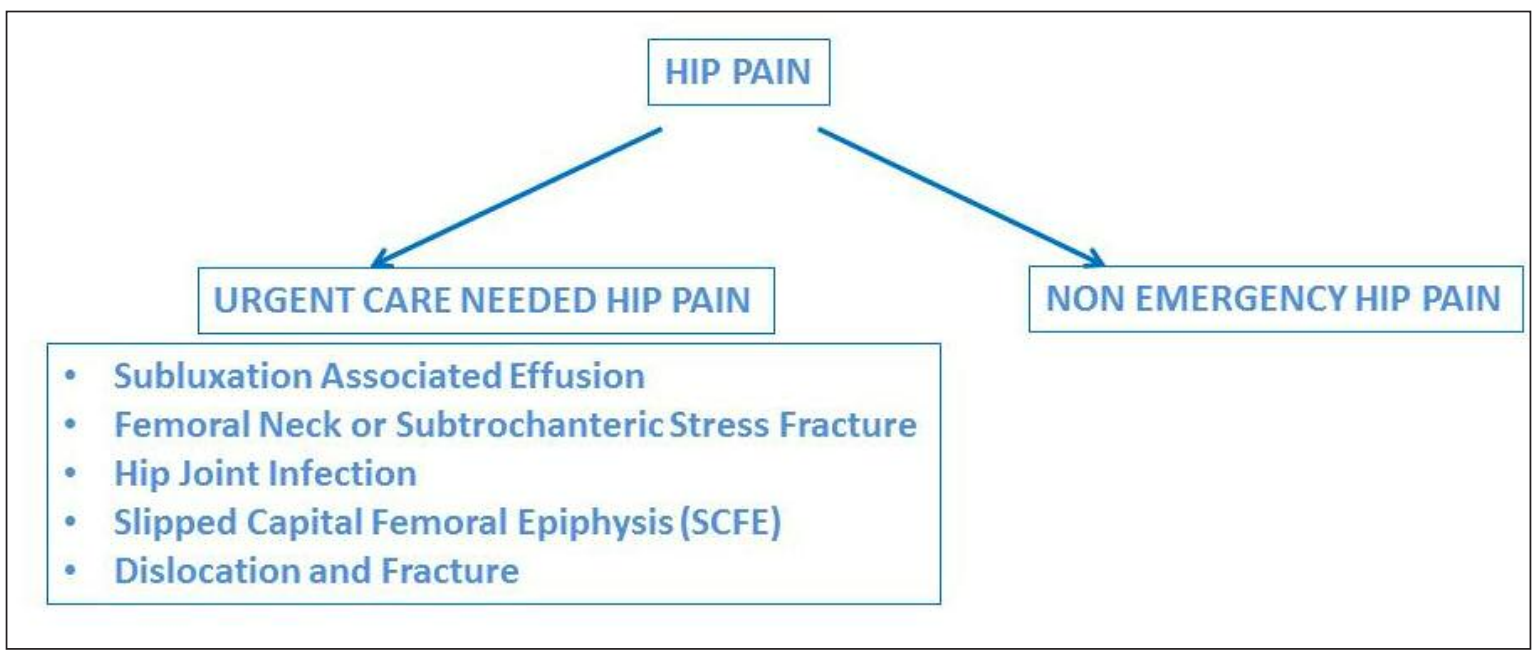

Figure 1. Hip Pain According to Urgent Care Need. 


\section{A. J. Stubbs et al.}

Table I. Findings Support Intra-articuar Pathology.

- Pain 'C sign'

- Asymmetric ROM

- Positive provocative tests

- Functional hemipelvic muscle weakness

tional hemipelvic muscle weakness, then we suspect intraarticular pathologies (Table I). These clinical findings are confirmed with radiographic findings. If there are soft radiographic findings with pelvis, lumbar, radiculopathic pain, hip range of motion is symmetric, negative provocative tests and selective muscle weakness/dysfunction, then we should suspect extraarticular pathologies (Figure 2).

II. Differentiation of Arthritic and Non-Arthritic Hip Pain: The physical examination is similar but ROM might be much more affected in the arthritic hip than non-arthritic. Differentiation can be done by radiologic findings ${ }^{9}$. Non or mild arthritic hip pain can be addressed by arthroscopic treatment; however, the severity of hip arthritis may negatively affect the outcome of hip arthroscopy ${ }^{10}$. The severity of the arthritis in the hip can be classified with the Tönnis Radiologic Classification as "Mild moderate and severe"11. The degree of osteoarthritis of the hip joint is as- sessed by the Authors using the Tönnis radiological classification and some additional signs of degeneration (Figure 3 ) including a central acetabular cotyloid osteophyte (the saber tooth sign) best visualized on the AP view, remodeling of the superolateral acetabulum (the seagull sign), sclerosis of the inferior acetabulum (the hammock sign), remodeling of the inferior femoral neck, and osteophytic changes of the femoral head fovea and posterosuperior femoral head-neck junction. Joint space loss under $2 \mathrm{~mm}$ is a threshold for hip arthroscopy contraindication (Figure 4) ${ }^{12}$.

Most of the cartilage loss can be seen at weight bearing area but non weight bearing but under stress areas of the hip cartilage should be assessed with joint space ratio test in the Faux-profile view also ${ }^{12}$ (Figure 4 b).

\section{Non Arthritic or Mild Arthritic Hip Pain}

With the suspicion of intra-articular pathology and after elimination of arthritis in hip joint, non or mild arthritic hip pain can be addressed. This type of pain can be classified by structural and most of them can be treated by defined arthroscopic or open procedures. Most of them have similar findings preoperatively (Figure 5).

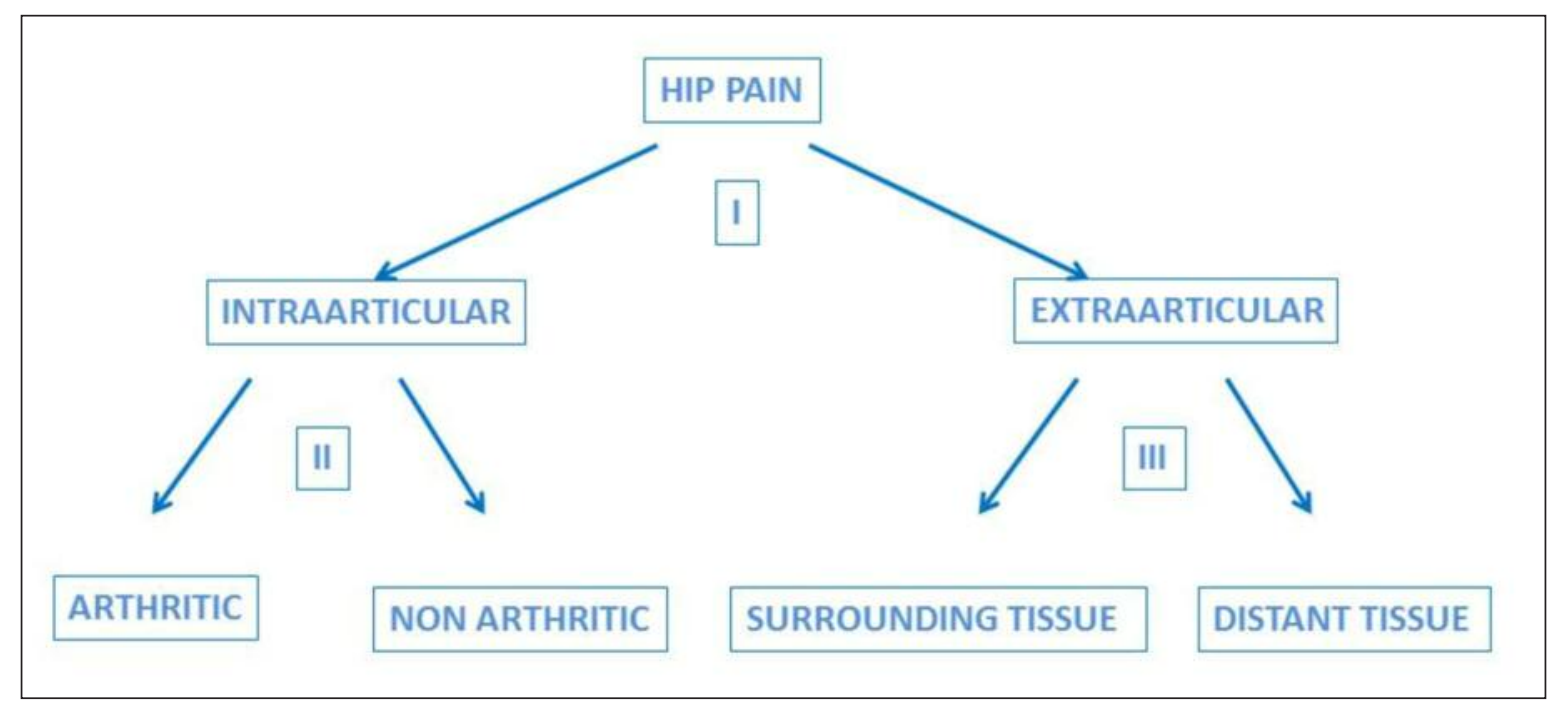

Figure 2. Hip Pain According to Intra- or Extra-articular Causes.

The 5 radiographic signs of arthritis in the hip

1. Posterosuperior femoral headneck junction remodeling sign.

2. Seagull sign.

3. Saber tooth sign.

4. Hammock sign.

5. Inferior femoral neck remodeling sign.

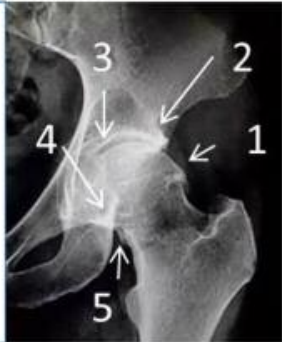

Figure 3. Specific Radiographic Signs of Arthritis in the Hip. 


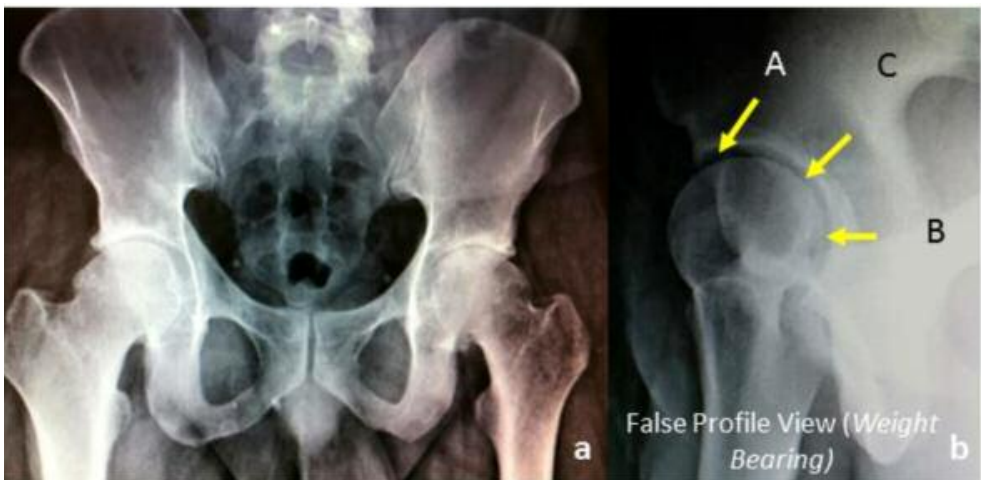

a. Joint Space Narrowing

b. Joint Space Ratio Test

If $A / B>1, O K$

If $A=B, \quad O K$

If $A / B<1$, Consider

arthritis

If $\mathrm{B}=0$, Consider coxa

profunda

If $\mathrm{C}=0$, Consider

Inflammatory /PVNS

Figure 4. Joint Space Narrowing and Joint Space Ratio Test.

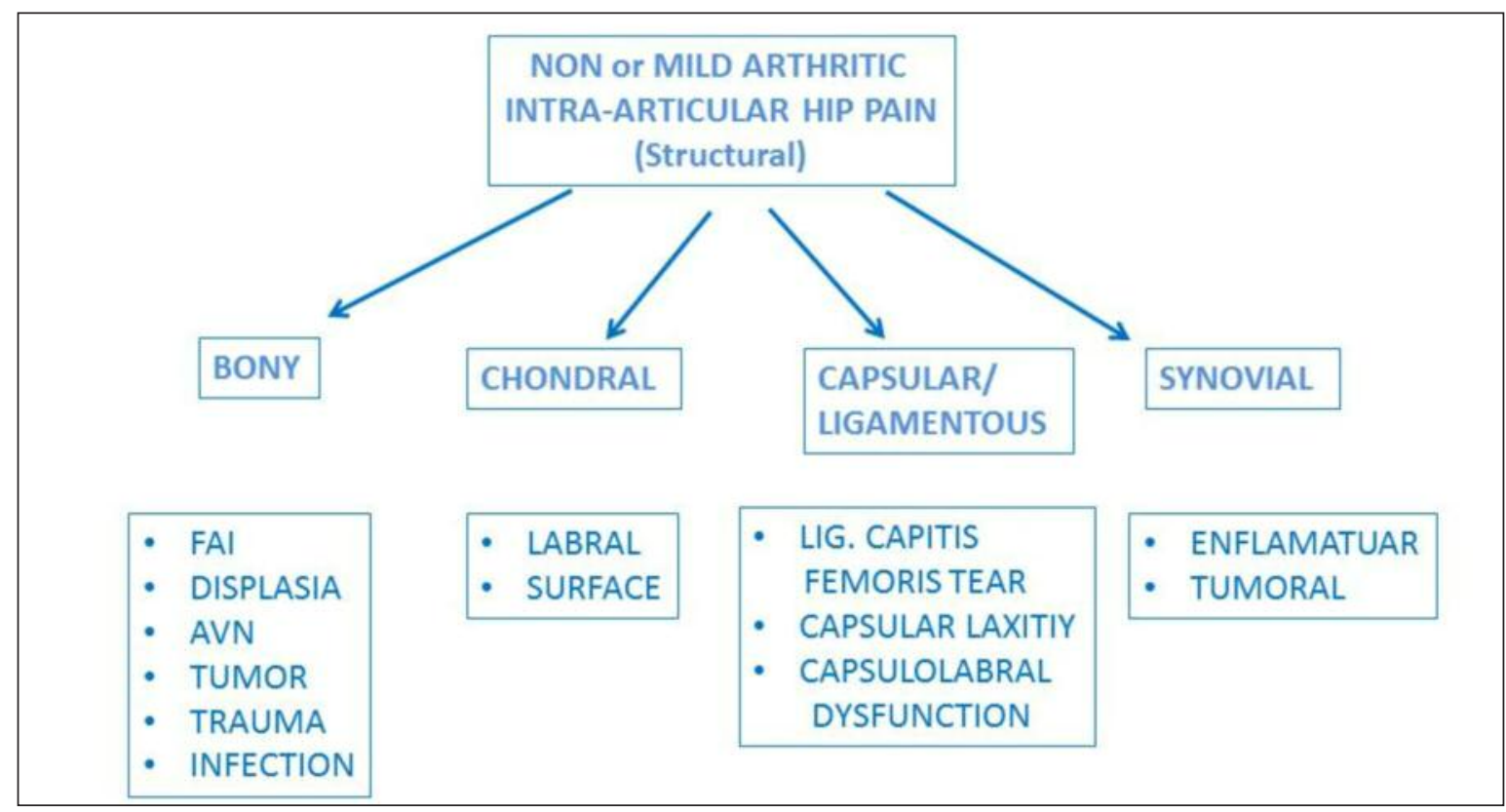

Figure 5. Non or Mild Arthritic Intra-articular Hip Pain Differential Diagnosis (Structural Classification).

Bony Structural Pathologies: Pathologies typically are classified according to structures but almost all cases have a mix of pathologies. A bony impingement or dysplasia may cause surface cartilage and labral cartilage damage and synovial inflammation. On the other hand, chondral damage is associated with subchondral bony changes. Synovial and inflammatory diseases may cause chondral lesions. So classifying the pathologies is important for comprehension of the pathologies and elimination at differential diagnosis but surgeon should know that especially in the hip joint he will face a multi-structural pathology.

Femoroacetabular Impingement (FAI): In assessing the pathology, classification as Cam or Pincer is important but a majority of cases should be considered as "mixed impingement" cases. Patients should be treated according to findings of preoperative evaluation as well as intraoperatively and fluoroscopically assessed findings. Senior Author uses a treatment algorithm for FAl at hip arthroscopy which is shown in the Figure 8.

Tips (HERE) History: Groin pain, limit motion activities and sports. Examination: Provocative tests positive. Radiology: Overcoverage of the acetabulum and/or abnormal hip neck morphology. Seconder changes of impingement. Lesions caused by impingement as labral tears, cysts, chondral lesions. Expectation: Preventing pain and early arthritis of the hip by addressing impingement and seconder pathologies.

\section{Dysplasia}

Tips (HERE) History: Symptoms arise from the anterior labral tear and cartilage damage which is similar to those of femoroacetabular impingement (FAI). Additional Symptoms may be instability, weakness, trochanteric symptoms due to abductor dysfunction and fatigue. Examination: Clinical examination may be normal, but symptoms can created by impinge- 
ment test similar to FAI. Trendelenburg sign and coxalgic gait are additional examinational findings. Radiology and Laboratory: Radiology is the most common assessment tool. The lateral center edge (LCE) angle is considered dysplastic below $20^{\circ}$; the Tönnis (sourcil) angle is abnormal above $10^{\circ}$. MRI of cartilage (dGEMRIC) or hip arthroscopy can be a diagnostic tool to identifying candidates for pelvic reorientation. Expectation: Long and painless serving of the native hip. Injections, Arthroscopic treatment of intraarticular pathologies and bony reconstructions with periacetabular osteotomy (PAO) and Femoral Osteotomies or joint reconstruction can be done according to stage of the disease ${ }^{13}$.

\section{Avascular Necrosis (AVN)}

Tips (HERE) History: Corticosteroid use, autoimmune disorders, alcohol abuse, smoking, and coagulation disorders, Previous hip surgery or trauma to hip should be assessed as risk factors. In the early stages it is asymptomatic. After it becomes symptomatic deep groin pain is the most common symptom. Examination: Physical examination may be normal but according to disease stage hip motion may be painful and limited, especially internal rotation. Radiology and Laboratory: In the early stages radiographs may be normal. At MRI necrotic-viable bone interface can be seen. Expectation: Prevention of future necrosis and restoration of the sequelae ${ }^{14}$.

\section{Tumors}

Tips (HERE) History: Benign and malign tumors of the bone can be exactly realized by imaging studies but pain at night and at rest can be helpful at history. Examination: is usually non-specific. Radiology: Some of them can be easily seen and some of them might be hidden on plain X-rays and seen at MRI, CT or Scintigraphic studies. The majority of tumors in the pelvis are malignant while in the proximal femur majority of the tumors are benign ${ }^{15}$. Osteoid osteoma and bone cysts can be treated by arthroscopy assisted surgery ${ }^{16,17}$.

Chondral Structure Pathologies: Almost all of the chondral, capsular, ligamentous and synovial pathologies can be addressed arthroscopically so exact decision of treatment can be done after identifying the pathology by arthroscopy (Figure 8).

\section{Labral Pathologies}

Tips (HERE) History: Most patients have sharp, doll groin pain, exaggerated by hip motion pain can be occasionally described at buttock. Examination: Limping, Trendelenburg sign, impingement sign and relief with intraarticular injection. Radiology: The most reliable study for diagnosis of labral tears appears to be small-field magnetic resonance arthrography (MRA). Expectation: Relieve of the pain with fixation of the labrum and elimination of the cause of labral damage
Acetabular or Femoral Surface Chondral Pathologies: Articular cartilage defects have limited healing capacity. Cartilage lesions of the hip are due to several causes like FAI, Dysplasia or inflammatory arthritis and cartilage lesion type and location differs according to cause. In CAM FAI abnormal femoral bump contacts with acetabular cartilage and causes delamination of the cartilage. Pincer impingement is a more labral sacrificing, chondral sparing deformity that typically involves repeated impingement of the anterior femoral head and neck junction on the acetabulum resulting in a lever arm on the posteroinferior acetabulum resulting in the so-called "contre-coup lesion". Inflammatory diseases cause central and global cartilage loss. In dysplasia, both the acetabular and femoral weight bearing areas have cartilage lesions.

Tips (HERE) History: Pure chondral injuries may not present with severe pain or symptoms because cartilage tissue has no nociceptive receptors unless there is a loose body or osteochondral lesion with subchondral bone involvement; however, synovial irritation may cause pain. Examination: There is no specific examination to assess cartilage damage but tests for the cause of the chondral lesion can be done. Radiology: Plain radiographs are the most useful for revealing the causes of chondral injury and severe chondral lesions. Mild to moderate chondral lesions can be better visualized by delayed gadolinium-enhanced MRI ${ }^{18}$ Expectation: Preventing arthritis by reconstruction or regeneration of the articular cartilage by the techniques of chondroplasty, abrasion arthroplasty, osteochondral drilling, osteoarticular autograft or allograft, hemicap resurfacing, autologous chondrocyte implantation $(\mathrm{ACl})$, or microfracture ${ }^{19}$.

\section{Capsular/Ligamentous Pathologies}

Ligamentum Teres (LT) Tears: The role of the ligamentum teres is more important when the other stabilizers of the hip have some deficiency ${ }^{20}$.

Tips (HERE) History: Completely non-specific and same with intra-articular symptoms. But painful clicking, locking or giving way can be assessed. Examination: Log-roll test, resisted straight-leg raise and ligamentum teres tests can be assessed ${ }^{21}$. Radiology: MR and CT arthrogram are helpful rather than MRI or $\mathrm{CT}$ alone. Adequate assessment of the $\mathrm{LT}$ required direct arthroscopic visualization and careful probing. Expectation: Relieving symptoms. Recommended treatment for LT tears has been simply debridement with either mechanical shavers or radiofrequency with concomitant anterior capsulorraphy ${ }^{22}$.

Capsular Laxity: Microinstability of the hip joint due to repetitive axial rotation and rotation of the capsule is a common but underdiagnosed condition.

Tips (HERE) History of overuse and supra physiologic activities of the hip joint. Examination: Painful passive hip extension and external rotation. Radiology: At MRA, Anterior capsule thinning and widening in joint recess ${ }^{23}$. Expectation: Preventing micro instability by addressing intraoperative pathologies and plication of the capsule 24 . 


\section{Synovial Pathologies}

Inflammatory Diseases: There are many inflammatory diseases that can affect hip joint.

Tips (HERE) History: Positive family history. Previous diagnosis for other joints. Joint stiffness. Examination: Similar with other arthritis causes in the hip but the other joints and remote findings of inflammatory arthritis can be helpful as rheumatoid hand, Heberden nodules, psoriatic plates, etc. Radiology and Laboratory: There is non-specific radiographic changes among hip joint but central joint space loss at false profile images can be assessed for inflammatory diseases (Figure 4). Specific immunologic and biochemistry studies can be done for revealing the underlying inflammatory pathology. Expectation: Controlling the inflammatory process in the hip joint with systemic medication. Addressing the intra-articular pathologies caused by inflammatory process.

Tumoral Lesions of Synovia: Synovial tumor based lesions are rare but these lesions should be kept in mind in differential diagnosis.

Tips (HERE) History and Examination can varies and mostly nonspecific. Radiology: Some of the aggressive lesions can be visualized by plain $X$ rays but MRI is the valuable tool for synovial pathologies. Synovialbased tumor-like lesions can be revealed by MR signal changes, such as the hemosiderin within Pigmented villonodular synovitis (PVNS) or the cartilage within synovial chondromatosis ${ }^{25}$. Expectation: Elimination of the tumor process via surgical and oncologic treatments.

Loose Bodies: Loose bodies can originate from either traumatic injury, degenerative changes, or other disease processes such as Perthes, spondyloepiphy- seal dysplasia, or osteonecrosis ${ }^{19}$.

Tips (HERE) History: Patients describe mechanical symptoms including catching, locking, clicking, or giving way. Examination: Asymmetry in the hip joint motion. Antalgic gait.

Radiology can reveal some of the loose bodies but the exact diagnosis can be done by MRI. Expectation: The symptomatic loose bodies within the hip can cause the destruction of hyaline cartilage with resultant degenerative arthritis. Before destruction of the cartilage the removal of the loose bodies is the goal and the expectation. Arthroscopy is the emerging gold standard for removal of a loose body from a hip joint.

III. Differentiation of Extraarticular Pathologies: Hilton's Law, simply stated, The nerve supplying the muscles surrounding a joint also innervates the joint supports the theory that the surrounding tissue of a joint may cause or mimic intra-articular pathologies or vice versa ${ }^{26}$. Extra-articular hip pain can be assessed by structural surrounding and distant tissues as well as approach with the pain side as anterior, lateral or posterior pain (Figure 6).

\section{Extra-Articular Causes of Hip Pain}

\section{Lateral hip pain}

Greater Trochanteric Pain Syndrome (GTPS): Includes four conditions: greater trochanteric bursitis, gluteus medius - minimus tears, and external coxa saltans ${ }^{27}$.

Tips (HERE) History: Lateral hip pain with or without snapping and Trendelenburg sign can be observed. Examination: Provocative tests at physical examina-

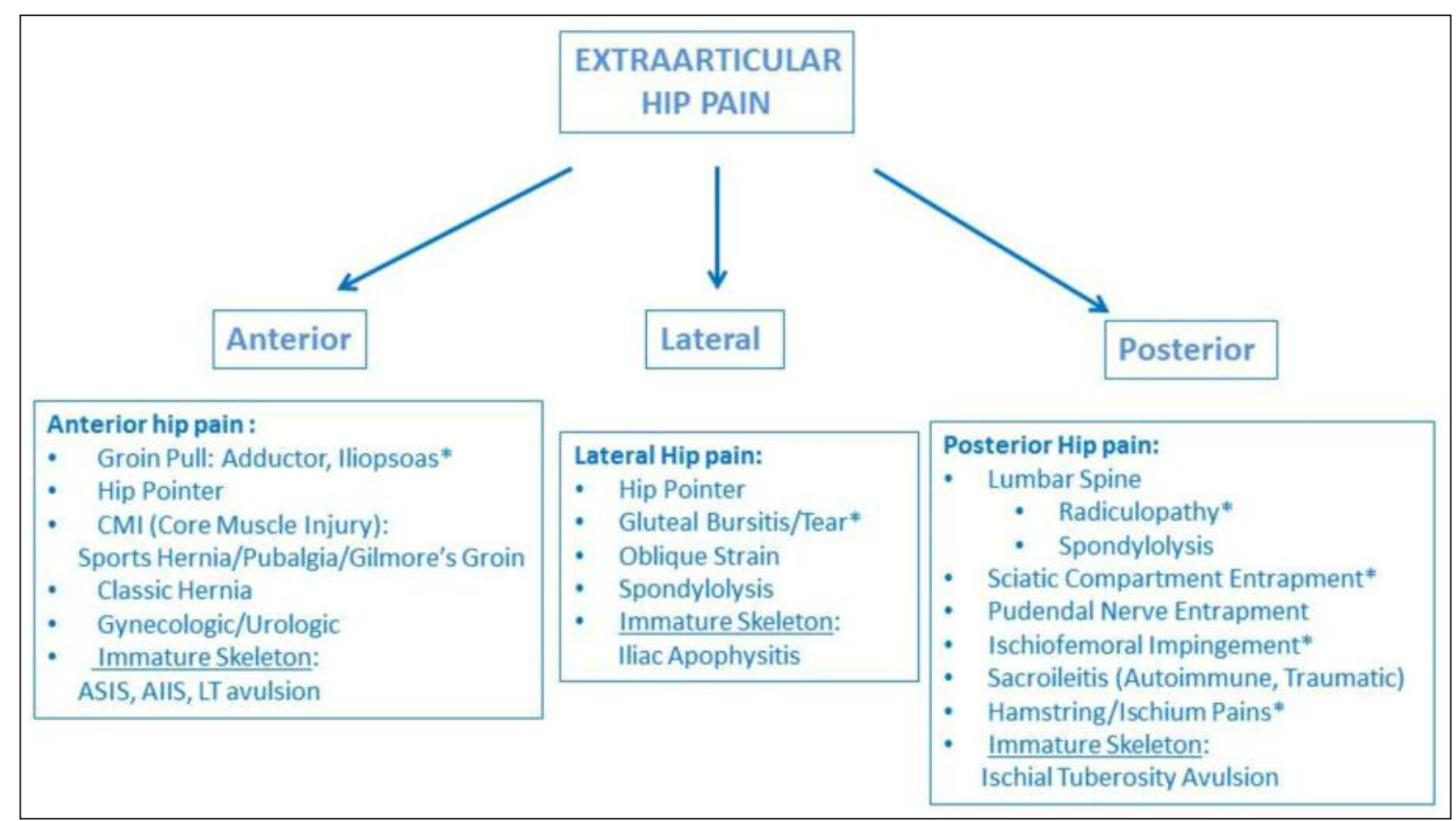

Figure 6. Evaluation of extraarticular hip pain according to pain side.

* Can be treated endoscopically. 


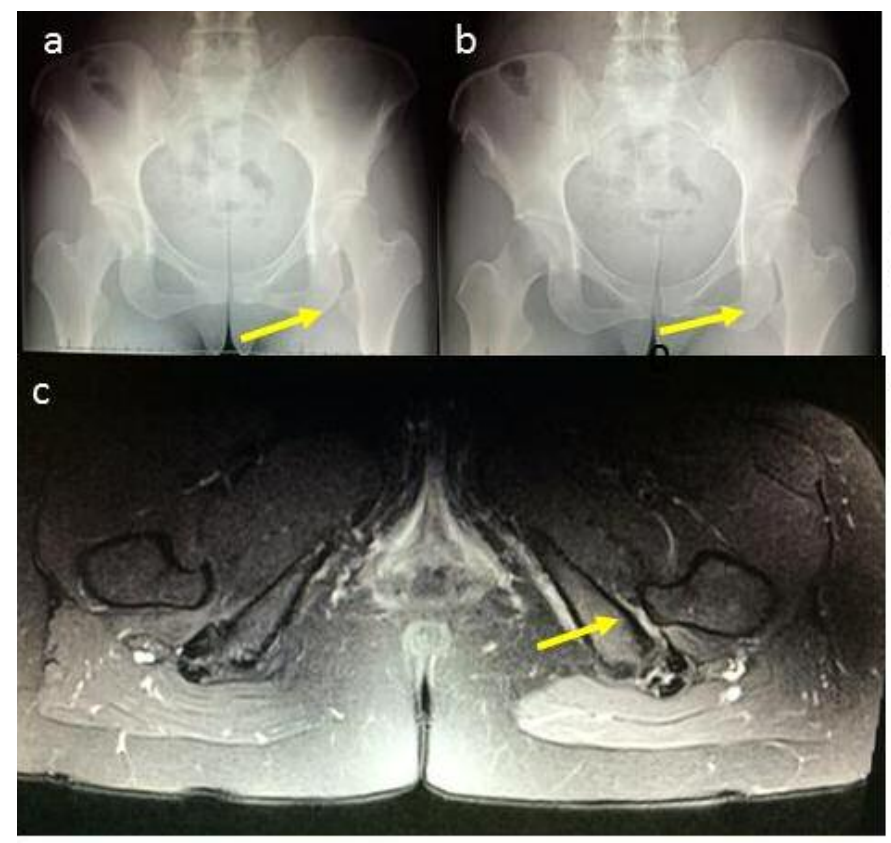

Left Ischiofemoral Impingiment

a. Narrowing of the space on Xray

b. More narrowing with single leg standing (Flamingo view)

c. Narrowing and Edema of the quadratus femoris muscle at MRI

Figure 7. Radiologic Evaluation of the Ischiofemoral Impingement.

tion are important for proper diagnosis. Radiology and Laboratory: After classical radiographs, dynamic ultrasound and MRI are useful to reveal pathology 28 . Expectation: Revealing of symptoms by treatment: Conservative with anti- inflammatory drugs, physical therapy, home exercises, and steroid injections. With resistant cases, endoscopic debridement of the bursitis, release of the ilio-tibial band, and repair of the tears can be performed 29 .

Anterior Hip Pain: It is important to differentiate the hip pain from other organ pains. Core Muscle Injury: Sports Hernia/Pubalgia/Gilmore's Groin, classical inguinal hernias and gynecologic or urologic problems can be radiate as anterior hip pain. Hip surgeon should assess these systems with the history and also examine these and refer to the related physician when necessary. The mostly encountered anterior hip pain cause is related with iliopsoas tendinitis or internal snapping syndrome.

Tips (HERE) History: Audible click and/or pain is occurred while the iliopsoas tendon moving over the anterior hip structures. Examination: Anterior hip or groin pain, weakness with resisted hip flexion in abduction, or symptomatic clicking or snapping with a positive iliopsoas test. Radiology: Conventional $X$ rays, bony prominence, Dynamic ultrasound and MRI can show structural changes inside the muscle. Expectation: Relieving of the symptoms. If the patient does not benefit from conservative management such as drugs, physical therapy and injections, then an endoscopic release of the iliopsoas may be considered at insertion site or at pelvic rim ${ }^{30}$.

\section{Posterior Hip Pain}

Deep Gluteal Syndrome: There is a wide spectrum of sciatic nerve entrapment causes which is referred to as deep gluteal syndrome.

Tips (HERE) History: Unable to sit more than half hour, paresthesias and/or radicular pain in the affected limb. Examination: Posterior hip tenderness with palpation and exaggeration of the symptoms with piriformis stretching tests. Pain which generated from spine, sacroiliac or hip joint should be excluded. Radiology: MRI may reveal intensity changes at piriformis muscle or space occupying lesion around the sciatic nerve. Expectation: Relieving the symptoms conservatively as drugs, injections and physical therapy or in resistant cases endoscopic sciatic nerve release can be performed ${ }^{31}$.

\section{Ischiofemoral (IF) Impingement}

Tips (HERE) History: Pain at the back of hip joint, pain can be radiate to anterior, groin or distal. mechanical symptoms, neurologic symptoms along sciatic nerve Examination: ischiofemoral impingement Tests (Johnson Test, Dynamic IF Impingement Test) Radiology: Valgus neck, cystic or sclerotic changes at lesser trochanter or ischial tuberosity ischiofemoral space calcification. Ischiofemoral space narrowing with Flamingo view. MRI; ischiofemoral space narrowing, edema signal pattern within IF space, degenerative signal (edema, tearing, fatty change) within quadratus femoris muscle. Tendinopathy (edema and partial tears), changes at hamstring origin ${ }^{32,33}$ (Figure 7). Expectation: Reliving the symptoms by activity modification, gait training, hip bracing, injection of IF space, endoscopic surgical decompression.

\section{Treatment Algorithm}

Diagnosis and treatment of the hip pain is interwoven. Diagnosis can be change according to response of the treatment. Conservative treatment consist of ac- 


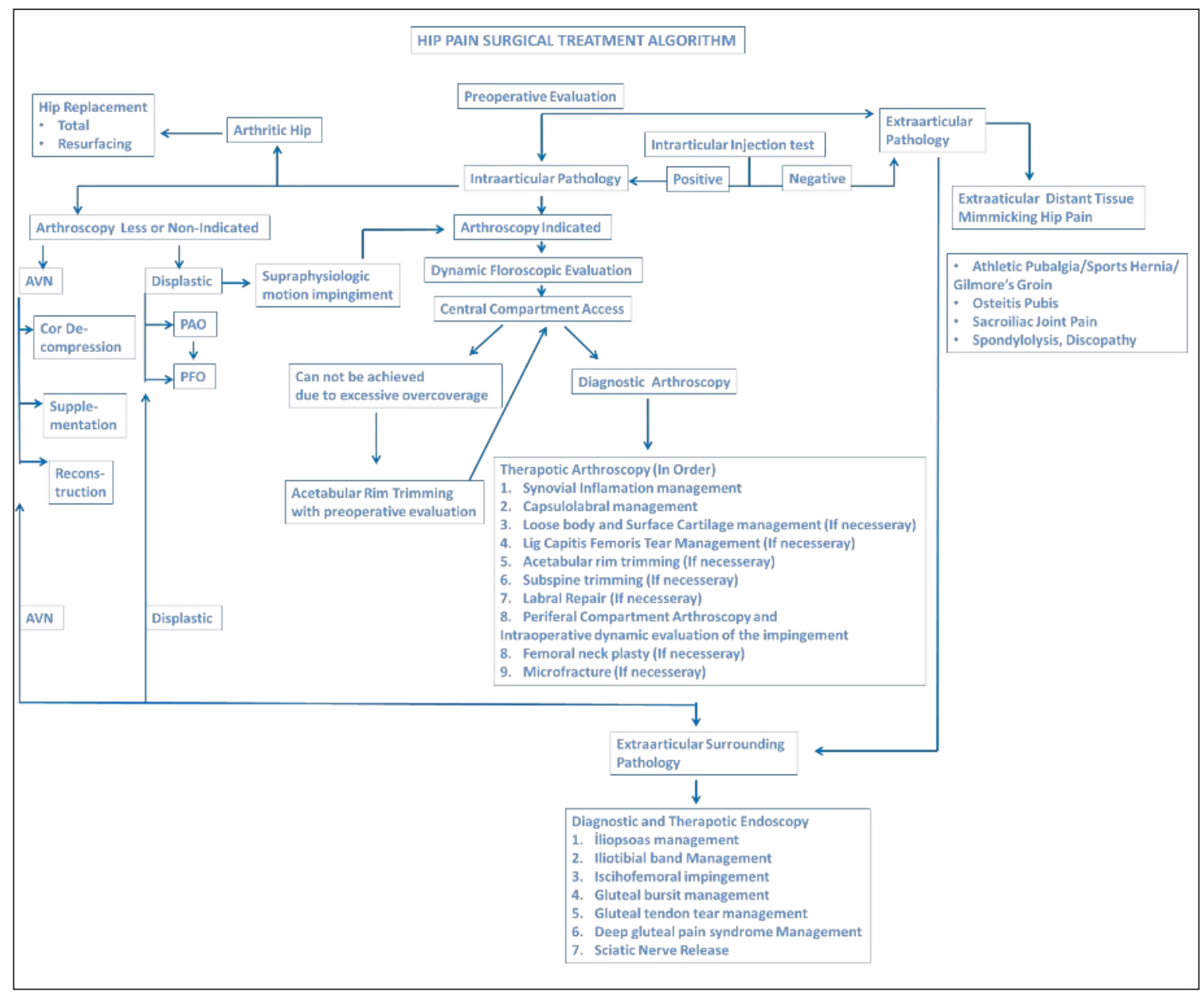

Figure 8. Surgical Treatment Algorithm for Hip Pain.

tivity modification, resting, drugs, physical therapy, exercises. Invasive treatments consist of injection of anesthetics, steroids, and biologics to the pathology generators. Relief of the symptoms sometimes treat the condition and sometimes indicate the real pathology for surgical treatment (Figure 8). Surgical treatment of the hip pain should be followed by dedicated rehabilitation program.

The study was conducted according to international the ethical standards ${ }^{34}$.

\section{References}

1. Lachiewicz PF, Salvati EA, Hely D, Ghelman B. Pathological dislocation of the hip in neurofibromatosis. A case report. J Bone Joint Surg Am. 1983;65:414-415.

2. Bierma-Zeinstra SM, Bohnen AM, Verhaar JA, Prins A, GinaiKaramat AZ, Laméris JS. Sonography for hip joint effusion in adults with hip pain. Ann Rheum Dis. 2000;59(3):178-82.

3. Egol KA, Koval KJ, Kummer F, Frankel VH. Stress fractures of the femoral neck. Clin Orthop Relat Res. 1998;(348):72-8. Review.

4. Ibn Yacoub Y, Amine B, Hajjaj-Hassouni N. Bilateral septic arthritis of the hip with osteitis and psoas abscess in a 17-yearold adolescent. J Pediatr Orthop B. 2011;20(4):238-41.
5. Kocher MS, Zurakowski D, Kasser JR. Differentiating between septic arthritis and transient synovitis of the hip in children: an evidence-based clinical prediction algorithm. J Bone Joint Surg Am. 1999;81(12):1662-70.

6. Mathews CJ, Weston VC, Jones A, Field M, Coakley G. Bacterial septic arthritis in adults. Lancet. 2010 Mar 6;375(9717) 846-55. doi: 10.1016/S0140-6736(09)61595-6. Review.

7. Dalla Vestra M, Rettore C, Sartore P, Velo E, Sasset L, Chiesa $G$, et al. Acute septic arthritis: remember gonorrhea. Rheumatol Int. 2008 Nov. 29(1):81-5.

8. Loder RT, Aronsson DD, Weinstein SL, Breur GJ, Ganz R, Leunig M. Slipped capital femoral epiphysis. Instr Course Lect. 2008;57:473-98. Review.

9. Bardakos NV, Villar RN. Predictors of progression of osteoarthritis in femoroacetabular impingement: a radiological study with a minimum of ten years follow-up. J Bone Joint Surg Br. 2009;91(2):162-169.

10. Mofidi A, Shields JS, Stubbs AJ. Central acetabular osteophyte (saber tooth sign), one of the earliest signs of osteoarthritis of the hip joint. Eur J Orthop Surg Traumatol. 2011;21(2):71-74.

11. Tönnis D, Heinecke A. Acetabular and femoral anteversion: relationship with osteoarthritis of the hip. J Bone Joint Surg Am. 1999;81(12):1747-1770.

12. Howse $E$, Stubbs $A$ J. Imaging in Hip Preservation Surgery $P$ 17 AANA Advanced Arthroscopic Surgical Techniques. The Hip / [edited by] J. W. Thomas Byrd, Asheesh Bedi, Allston J. 
Stubbs. SLACK Incorporated, [2016]

13. Gala L, Clohisy JC, Beaulé PE. Hip Dysplasia in the Young Adult. J Bone Joint Surg Am. 2016;6;98(1):63-73. doi: 10.2106/JBJS.O.00109. Review.

14. Van Thiel G, Mather RCThe Treatment of Osteonecrosis in the Hip. OperTechSportsMed. 23:222-230.

15. Bloem JL, Reidsma II. Bone and soft tissue tumors of hip and pelvis. Eur J Radiol. 2012 Dec;81(12):3793-801. doi: 10.1016/j.ejrad.2011.03.101. Epub. 2011;27. Review.

16. Tamam C, Howse EA, Tamam M, Barnes RH, Kelsey TJ, Perry B, Stubbs AJ. Arthroscopic Excision of Acetabular Osteoid Osteoma: Computer Tomography-Guided Approach. Arthrosc Tech. 2015;9;4(2):e101-5.

17. Jamali AA, Fritz AT, Reddy D, Meehan JP. Minimally invasive bone grafting of cysts of the femoral head and acetabulum in femoroacetabular impingement: arthroscopic technique and case presentation. Arthroscopy. 2010;26(2):279-85.

18. Bittersohl B, Hosalkar HS, Haamberg T, et al. Reproducibility of dGEMRIC in assessment of hip joint cartilage: a prospective study. J Magn Reson Imaging. 2009;30:224-228.

19. Yen YM, Kocher MS. Chondral lesions of the hip: microfracture and chondroplasty. Sports Med Arthrosc. 2010;18(2):839.

20. Martin RL, Palmer I, Martin HD. Ligamentum teres: a functional description and potential clinical relevance. Knee Surg Sports Traumatol Arthrosc. 2012;20:1209-14.

21. O'Donnell J, Economopoulos $\mathrm{K}$, Singh $\mathrm{P}$, et al. The ligamentum teres test: a novel and effective test in diagnosing tears of the ligamentum teres. Am J Sports Med. 2014;42:138-43.

22. Bardakos NV, Villar RN. The ligamentum teres of the adult hip. J Bone Joint Surg Br. 2009;91:8-15.

23. Magerkurth O, Jacobson JA, Morag Y, Caoili E, Fessell D, Sekiya JK. Capsular laxity of the hip: findings at magnetic resonance arthrography. Arthroscopy. 2013;29(10):1615-22.
24. Ranawat AS, Sekiya JK. Arthroscopic capsular plication and thermal capsulorrhaphy. In: Sekiya JK, Safran M,Ranawat AS, Leunig M, eds. Techniques in hip arthroscopy and joint preservation surgery. Ed 1. Philadelphia: Saunders/ Elsevier. 2010;131-138.

25. Bancroft LW, Peterson JJ, Kransdorf MJ. MR imaging of tumors and tumor-like lesions of the hip. Magn Reson Imaging Clin N Am. 2005;13(4):757-74.

26. Moore KL, Dalley AF, Agur AMR. Clinically Oriented Anatomy, (2010) 6th Ed, p.633

27. Strauss EJ, Nho SJ, Kelly BT: Greater trochanteric pain syndrome. Sports Med Arthrosc. 2010;18(2):113-119.

28. Yen YM, Lewis CL, Kim YJ. Understanding and Treating the Snapping Hip. Sports Med Arthrosc. 2015;23(4):194-9.

29. Redmond JM, Chen AW, Domb BG. Greater Trochanteric Pain Syndrome. J Am Acad Orthop Surg. 2016;24(4):231-40.

30. Brandenburg JB, Kapron AL, Wylie JD, Wilkinson BG, Maak TG, Gonzalez CD, Aoki SK. The Functional and Structural Outcomes of Arthroscopic lliopsoas Release. Am J Sports Med. 2016 Feb 12.

31. Martin HD, Reddy M, Gómez-Hoyos J. Deep gluteal syndrome. J Hip Preserv Surg. 2015;2(2):99-107.

32. Torriani M, Souto SC, Thomas BJ, Ouellette H, Bredella MA. Ischiofemoral impingement syndrome: an entity with hip pain and abnormalities of the quadratus femoris muscle. AJR Am J Roentgenol. 2009;193(1):186-90.

33. Tosun O, Algin O, Yalcin N, Cay N, Ocakoglu G, Karaoglanoglu M. Ischiofemoral impingement: evaluation with new MRI parameters and assessment of their reliability. Skeletal Radiol. 2012;41(5):575-87.

34. Padulo J, Oliva F, Frizziero A, Maffulli N. Muscles, Ligaments and Tendons Journal. Basic principles and recommendations in clinical and field Science Research: 2016 Update. MLTJ. 2016;6(1):1-5. 